\title{
Essential contraceptives: public movement and technical advocacy
}

\author{
Lindsay Edouard
}

\section{Summary}

User choice is central to contraceptive practice, as opposed to therapeutic care where the view of the prescriber tends to prevail. Provider organisations have to make difficult decisions in selecting the methods of contraception that are offered, particularly with the multitude of new products and the controversies that have surrounded the value of some of them. The World Health Organization (WHO) Model List of Essential Medicines is a valuable tool in strengthening the provision of contraceptive commodities as part of international development efforts.

\section{Consumerism}

In the Britain of 1983, consumerism had already found its place in contraceptive practice. The Consumers' Association published the Which? Guide to Birth Control, which recognised the importance of individual choice, referring to "lifestyle and needs rather than ... any absolute standard" in the selection of a contraceptive method. Its preface went as far as making analogies to other examples of the preferred choice of individuals: electricity or gas, cooking for two or eight and finally, wall oven or solid fuel centrepiece. ${ }^{1}$ This seemingly flippant comparison illustrated the difficult situation encountered by individuals who, as consumers in a market economy, still had to exercise method choice in the implementation of rights to contraception whilst ensuring a sound rationale for their selection of a product.

Medical professionals might often be uncomfortable with consumer issues impinging on their practice, as had been experienced in France through their hostility to Que choisir?, a similar consumer publication. ${ }^{1}$ Being jealous of their role in exercising clinical judgement in the selection of drugs to treat illness, medical professionals are often reluctant to delegate decision-making, even during a contraceptive consultation, to an individual whether as a patient with disease or as a healthy client. Since informed choice of the user plays a primordial role in contraceptive practice by enhancing effective use of a method, it is imperative to promote opportunities for individuals to exert that choice.

\section{Constraints}

The limited availability of contraceptive commodities in Britain in 1983 was exemplified by a most unfortunate situation whereby a substantial proportion of pharmacists failed to stock intrauterine contraceptive devices. This was out of keeping with the otherwise well-recognised role of the pharmacist as dispenser, counsellor or advocate for contraception, especially with regard to those individuals who did not access the clinical services. ${ }^{2}$ Conversely, serious doubts were being expressed on the value of innovative formulations of oral contraceptives, such as biphasics and triphasics, and newer progestogens that were

J Fam Plann Reprod Health Care 2008; 34(4): 269-270

Algiers, Algeria

Lindsay Edouard, FRCOG, FFSRH, Member of the Editorial Advisory Board

Correspondence to: Professor Lindsay Edouard.

E-mail: soranae@gmail.com not perceived as offering any advantage over existing types. ${ }^{3}$ Despite its commercial success as the most commonly used progestogen for oral contraception, levonorgestrel was being questioned in view of its marked adverse effects on lipoprotein metabolism leading to a lowered HDL2:LDL ratio, thought to increase the risk for atherosclerosis. ${ }^{4}$ As it would be years before the clinical significance of those biochemical changes could be determined, the consensus aimed for low-dosage formulations for minimal disturbance of the biochemical profile. With selection of a product ideally taking into account both the side effects being encountered and the hormonal state of the individual, "all 25 formulations of contraceptive pill are needed because of the great variation in the female metabolism". 5

Depot medroxyprogesterone acetate (DMPA) was enjoying great support in international circles as reflected by its entry to the List of Essential Drugs at the WHO meeting held in 1984. At its annual general meeting in April 1983, the National Association of Family Planning Doctors (NAFPD) was "bitterly disappointed by the action of the Minister of Health in rejecting the advice of the Committee on Safety of Medicines" that had recommended the extension of the licensing of DMPA for general use. ${ }^{6}$ Rightly, the matter was not laid to rest as manufacturers pursued the issue through a public hearing, "a procedure under the Medicines Act 1968 which has not been used in this way before, under which a pharmaceutical company has the right to a hearing in public if the Licensing Authority proposes to refuse a product licence for a drug contrary to the advice of the Committee on Safety of Medicines".7 By supporting DMPA and stating that there was "no reason why it should not be made available to any woman who wants it on the same basis as other recognised effective forms of contraception", 8 the NAFPD was a full decade ahead of intergovernmental commitments on sexual and reproductive health, rights and gender since this Association was already promoting availability of a wide range of methods and stressing the importance of the perspective of the client.

Even when contraceptive methods were readily available, their actual utilisation was often limited. Condom Sense, a "very educational and at the same time deliciously funny" film was included in the latest London Film Festival. Aiming to address myths that deter use of the male condom which is "the only contraceptive that can also help prevent disease", it used "plain, but never vulgar" English and actual people in real situations. ${ }^{9}$

\section{Current global concepts}

The Programme of Action of the International Conference on Population and Development, held in Cairo in 1994, included the aim of universal access to the widest possible range of safe and effective contraceptive methods by 2015 , thereby enabling individuals to exercise their right to informed choice for utilisation of the method that best meets their needs. The quest for a full range of contraceptive methods has major implications for research and development, especially in basic and applied biomedical science as well as in the social sciences, for "the improvement of existing and the development of new methods for regulation of fertility". 10 Therefore research 
should be supported by the donors that promote contraceptive services otherwise it might be perceived as unethical to apply methods in service delivery without contributing to contraceptive development.

By selecting HIV for its first-ever debate on a health issue the United Nations Security Council demonstrated, in 2002, the increasing importance of reproductive health. The resolution stated that "the HIV/AIDS pandemic, if unchecked, may pose a risk to stability and security" 11 and condom security was discussed. Furthermore, the rightsbased discourse has addressed practical aspects of advocacy to ensure accessibility, especially for disadvantaged groups, beyond mere availability of essential medicines. ${ }^{12}$ However, the inclusion of drugs pertaining to reproductive health in the WHO List has sometimes led to controversy, a prime example being the political saga regarding the listing of mifepristone and misoprostol in the oxytocics section. ${ }^{13,14}$ The addition of a footnote on cultural acceptability achieved a compromise. ${ }^{15}$

\section{Expanding contraceptive choice}

Whereas the physician has the role of selecting the best treatment in curative clinical practice, contraceptive services should normally use a very different approach, by placing the onus of the selection of a method on the individual client, following which the choice is considered by the practitioner. Therefore criteria for the selection of contraceptive methods should go beyond comparisons of efficacy, safety and cost by including perceived convenience, suitability, acceptability and other considerations that are likely to increase user satisfaction and continuation rates. While it is desirable to use an evidence-based approach, it should be acknowledged that it is extremely difficult to conduct randomised controlled trials to assess the long-term outcome and safety of contraceptive products.

In 2007, the 30th anniversary year of the List of Essential Medicines, the WHO Expert Committee on the Selection and Use of Essential Medicines agreed that "the approach to provision of contraceptives was a philosophy of choice and therefore required a wide range of options", as opposed to "identifying the minimum needed to provide health care". ${ }^{15}$ At the beginning of that meeting, an open session had been held for dialogue with stakeholders.

In 2007 a two-rod levonorgestrel-releasing implant and the combination injectable medroxyprogesterone acetate/estradiol cypionate were added to the WHO List that already included oral contraceptives, levonorgestrelonly emergency contraception, progestogen-only injectables, copper intrauterine devices, condoms and diaphragms. This wide range reflected commitment to the promotion of contraceptive choice. Despite its questioned status in Britain around 1983, DMPA has maintained its place on the Model List since 1984.

Revisions to the Model List occur about every 2 years using a well-defined set of procedures for the consideration of submissions. The ensuing list is commonly adapted at country level, using resources such as the WHO Essential Medicines Library and WHO Model Formulary, both for procurement in the public sector and for reimbursement in health insurance schemes. Availability of supplies is an important constraint. The increasing inclusion of contraceptive products in the WHO Model List has great potential to improve their accessibility in low-resource settings.

\section{Statements on funding and competing interests}

Funding None identified.

Competing interests The author supported expansion of the list of contraceptives during his participation in the 2007 meeting of the WHO Expert Committee.

\section{References}

1 Spencer B. The Which? Guide to Birth Control. Br J Fam Plann 1983; 9: 102

2 Chambers M, Chambers DM. Pharmacy contraception and the health care role. Br J Fam Plann 1983; 8: 148.

3 Pollitt Y. Affiliated Groups Meeting. Br J Fam Plann 1983; 9: 26-27.

4 Wynn V. In response to 'Levonorgestrel attack unjustified'. Br J Fam Plann 1983; 9: 66-67.

5 Friedmann B. Ninth Fertility Control Symposium. Br J Fam Plann 1983; 8: 144-147.

6 Anonymous. Minutes of AGM. Br J Fam Plann 1983; 9: 70-72.

7 Anonymous. Depo Provera - public hearing. Br J Fam Plann 1983; 8: 150.

8 Anonymous. NAFPD statement on Depo Provera. Br J Fam Plann 1983; 9: 68-69.

9 Anonymous. Condom sense. Br J Fam Plann 1983; 9: 49.

10 United Nations. Programme of Action Adopted at the International Conference on Population and Development, Cairo, 5 to 13 September 1994. Document A/CONF.171/13. Paragraphs 7.16, 7.23(a), 12.12. New York, NY: United Nations, 1994.

11 United Nations Security Council. Resolution 1308 (2000). Document S/RES/1308. New York, NY: United Nations, 2000.

12 Hogerzeil HV, Samson M, Casanovas JV, Rahmani-Ocora L. Is access to essential medicines as part of the fulfilment of the right to health enforceable through the courts? Lancet 2006; 368: 305-311.

13 Boseley S. US accused of trying to block abortion pills. The Guardian, 21 April 2005

14 Editorial. Abortion drugs must become WHO essential medicines. Lancet 2005; 365: 1826.

15 World Health Organization (WHO). The Selection and Use of Essential Medicines: Report of the WHO Expert Committee, 2007 Including the 15th Model List of Essential Medicines. WHO Technical Report Series; No. 946. Geneva, Switzerland: WHO, 2007; 48-52, 68, 81-88, 109, 113, 123-124, 147.

\section{BOOK REVIEW}

The Male Genitalia: A Clinician's Guide to Skin Problems and Sexually Transmitted Infections. Manu Shah with Ariyaratne Desilva. Oxford, UK: Radcliffe Publishing, 2008. ISBN13: 978-1-84619-040-7. Price: £29.95. Pages: 160 (paperback)

This is an interesting book by Manu Shah to guide on clinical and pathological conditions specific to male genitalia. I have a special interest in genital dermatoses and provide a specialist 'genital dermatoses' service jointly with my dermatology colleague. We have noted that high proportions (59\%) of cases attending this clinic are men. While expertise in female genital pathology is widespread among professionals providing specialist 'vulva clinics', there seems to be a paucity of specialist focus on similar conditions in men. This book is a welcome addition, and will increase familiarity with problems among men.

The layout of this book makes it very easy to read. There are 12 chapters, which cover a wide range of subjects such as normal anatomy and its variant, genital dermatoses, sexually transmitted infections (STIs), and psychological and psychiatric disorders. The first chapter includes an introduction to basic techniques in sexual history taking and genital examination. Pathological conditions are described precisely and illustrated with excellent photographs Dermatological manifestations of STIs and specific features of dermatological pathology are well described and illustrated. In an era of increasing STIs and HIV, such knowledge would certainly aid professionals.

The chapters on genital itching, problems with the foreskin and red glans penis would be a particularly useful guide for general practitioners and general practice nurses.

This book can be recommended as a reference guide to a wide range of health professionals who deliver sexual health services.

Reviewed by Ranjana Rani, MRCOG, FFSRH Consultant in Genitourinary Medicine and Lead Sexual Health, Tameside and Glossop Centre for Sexual Health, Ashton-under-Lyne, UK 